\title{
Review Article \\ Discovery of Antimalarial Drugs from Streptomycetes Metabolites Using a Metabolomic Approach
}

\author{
Siti Junaidah Ahmad, ${ }^{1}$ Mohd Badrin Hanizam Abdul Rahim, ${ }^{1}$ Syarul Nataqain Baharum, \\ Mohd Shukri Baba, ${ }^{3}$ and Noraziah Mohamad Zin ${ }^{1}$ \\ ${ }^{1}$ Programme of Biomedical Science, School of Diagnostic and Applied Health Sciences, Faculty of Health Science, \\ Universiti Kebangsaan Malaysia (UKM), 50300 Kuala Lumpur, Malaysia \\ ${ }^{2}$ Institute of Systems Biology (INBIOSIS), Universiti Kebangsaan Malaysia, 43600 UKM Bangi, Selangor, Malaysia \\ ${ }^{3}$ Department of Biomedical Science, Kulliyyah of Allied Health Sciences, International Islamic University Malaysia, \\ Jalan Sultan Ahmad Shah, 25200 Kuantan, Pahang, Malaysia \\ Correspondence should be addressed to Noraziah Mohamad Zin; noraziah.zin@ukm.edu.my
}

Received 28 July 2017; Accepted 30 August 2017; Published 16 October 2017

Academic Editor: Jean-Paul J. Gonzalez

Copyright (C) 2017 Siti Junaidah Ahmad et al. This is an open access article distributed under the Creative Commons Attribution License, which permits unrestricted use, distribution, and reproduction in any medium, provided the original work is properly cited.

\begin{abstract}
Natural products continue to play an important role as a source of biologically active substances for the development of new drug. Streptomyces, Gram-positive bacteria which are widely distributed in nature, are one of the most popular sources of natural antibiotics. Recently, by using a bioassay-guided fractionation, an antimalarial compound, Gancidin-W, has been discovered from these bacteria. However, this classical method in identifying potentially novel bioactive compounds from the natural products requires considerable effort and is a time-consuming process. Metabolomics is an emerging "omics" technology in systems biology study which integrated in process of discovering drug from natural products. Metabolomics approach in finding novel therapeutics agent for malaria offers dereplication step in screening phase to shorten the process. The highly sensitive instruments, such as Liquid Chromatography-Mass Spectrophotometry (LC-MS), Gas Chromatography-Mass Spectrophotometry (GC-MS), and Nuclear Magnetic Resonance $\left({ }^{1} \mathrm{H}-\mathrm{NMR}\right)$ spectroscopy, provide a wide range of information in the identification of potentially bioactive compounds. The current paper reviews concepts of metabolomics and its application in drug discovery of malaria treatment as well as assessing the antimalarial activity from natural products. Metabolomics approach in malaria drug discovery is still new and needs to be initiated, especially for drug research in Malaysia.
\end{abstract}

\section{Introduction}

Over the centuries, natural products including animals, plants, and mineral have played an important role in drug discovery and development for the treatment of human disease $[1,2]$. Streptomycetes are Gram-positive bacteria, which are widely distributed in nature and abundant in soil. This group of bacteria produces secondary metabolites such as antibiotics and their derivatives, which have been synthesized biosynthetically from the primary metabolites, have been applied towards combating pathogens and cancer $[2,3]$. Despite being used for years in the development of new therapeutic agents, finding potential novel compounds from the streptomycetes metabolites for the treatment of human disease such as malaria remains a great challenge.

Dereplication is a process used in recognising and eliminating the active substances that have already been studied in the early stage of the screening process [4]. This process is considered as a stage following the preliminary screening in discovering new pharmacologically active compounds in an extract from natural products [5]. Recently, metabolomics approach has been applied in the dereplication process $[6$, 7]. Nuclear magnetic resonance (NMR) spectroscopy- and mass spectrometry- (MS-) based metabolomics approaches are powerful tools that facilitate quick identification of both the targeted and untargeted metabolites present in a 
TABLE 1: List of antimalarial agent sources and their biological compounds.

\begin{tabular}{|c|c|c|c|}
\hline Actinobacteria & Compound & Testing approach & Reference \\
\hline Streptomyces ochraceus and Streptomyces bottropensis & Trioxacarcins (Trioxacarcin A, B C D) & In vitro testing & {$[20]$} \\
\hline Streptomyces sp. MSU-2110 & Coronamycins & In vitro testing & {$[21]$} \\
\hline Streptomyces NRRL 3052 & Munumbicins, E-4 and E-5 & In vitro testing & [22] \\
\hline Streptomyces NRRL 30562 & Munumbicin D & In vitro testing & [23] \\
\hline Streptomyces spectabilis BCC 4785 & Metacycloprodigiosin & In vitro testing & [24] \\
\hline Streptomyces sp. NRRL 30566 & Kakadumycin A & In vitro testing & [25] \\
\hline Streptomyces sp. SUK 10 & Gancidin-W & In vivo testing & [26] \\
\hline Streptomyces albidoflavus & Antimycin A18 & In vitro testing & [27] \\
\hline Streptomyces sp. CS, & bafilomycin $\mathrm{A}_{1}$ & In vitro testing & [28] \\
\hline
\end{tabular}

complex mixture of crude extract during the screening phase. Hence, these methods eliminate already well-known natural products from further isolation process [8].

Drug discovery from natural product utilizing metabolomics platform gives a significant tool in system biology. This allows researchers or pharmaceutical scientists to gain some insight about new potential pharmaceutical agents and to manipulate the factors within fermentation system in sustainable manner to select a desired metabolite [9]. The present review covers the metabolomics approach in drug discovery of malaria treatment and discusses the potential of natural antibiotic products from streptomycetes.

\section{Metabolomic Concept}

Metabolomics is a systematic, qualitative, and quantitative study of small bioactive molecules in organism, biological fluid, plants, and food matrices at specific time and under specific conditions [8]. This study is about all metabolites set within organism or tissue [10]. Metabolomics is a branch of "omics" technology that focused on high-throughput identification and quantification of small molecules metabolites in metabolome. Metabolome is a set of all small molecules of metabolites that are found in a cell, organ, or organism. These molecules include chemical entities such as peptides, amino acids, nucleic acids, carbohydrate, organic acids, vitamins, drugs, food additives, phytochemicals, and toxin [11].

Metabolites are divided into two types, primary metabolites and secondary metabolites. Primary metabolites are normally produced during the growth phase of the organism as well as during energy metabolism [12]. These primary metabolites such as carbohydrate, protein, amino acids, and fatty acids are vital for the cell and normally involve cell growth, development, and reproduction [13]. Secondary metabolites, on the other hand, are synthesized from the primary metabolites during certain condition and play a role in defence mechanism from pathogen and abiotic stress [14]. These low-molecular-weight metabolites $(<3 \mathrm{kDa})$ comprise a highly valuable class of compounds that can be used in many applications such as drugs (e.g., antibiotics, antitumor agents), agrochemical agents (e.g., pesticides), biofuel (e.g., oleoresin), and food additives (e.g., essential oils) [15]. It has been reported that the microbial secondary metabolites from fungus and bacteria exhibit medicinal value as an antimicrobial agent, sor example, Streptomyces kebangsaanensis that produce phenazine [16]. In general, metabolomics could be used to identify and to optimize the production of secondary metabolites. Information gathered from a metabolomics dataset can efficiently establish cultivation and production processes at a small scale which will be finally scaled up to a fermenter system.

\section{Streptomyces}

Streptomyces is the largest genus of Actinomycetes. Streptomyces is Gram-positive aerobic bacteria which produce a network of branched filaments called substrate mycelia and aerial mycelia. Their cell wall contains alanine, glutamic acid, glycine and LL-2, and 6-diaminopimelic acid (LL-DAP) which is an amino acid and its nucleus has more than $70 \%$ guanine and cytosine $(\mathrm{G}+\mathrm{C})$ content [17].

This Gram-positive bacteria produce secondary metabolites which have the potential to be used as source of natural antibiotic such as daptomycin. Moreover, the secondary metabolites produced by Streptomyces also have been shown to act as immunosuppressants (e.g., rapamycin), antifungals (e.g., amphotericin B), anticancers (e.g., doxorubicin), and antiparasitics (e.g., ivermectin) [18].

\section{Bioactive Compounds from Streptomycetes Metabolites}

Bioactive compounds from Streptomyces spp. have been used as source of natural antibiotic product. From the late 1940s to the 1960s, which is also called the golden age of antibiotics discovery era, many antibiotics were isolated from various Streptomyces species and entered clinical use [13]. One of the unique features of the genome in the Streptomyces species is the presence of biosynthetic gene clusters which encode enzymes that are involved in the production of secondary metabolites [19]. Examples of bioactive compounds produced by Streptomyces sp. are listed in Table 1.

Trioxacarcins are complex antibiotics that were first isolated in 1981 [29]. In later years, [20] has isolated trioxacarcins A, B, C, and D from marine streptomycetes and has tested the compounds against Plasmodium falciparum (P. falciparum). Out of these four compounds, trioxacarcins $A$ and D show extremely high antiplasmodial activity (with the $\mathrm{IC}_{50}$ value $1.6 \pm 0.1$ and $2.3 \pm 0.2 \mathrm{ng} / \mathrm{mL}$, resp.) which is comparable to the most active compound, artemisinin $\left(\mathrm{IC}_{50}\right.$ value $0.7 \pm$ 
$0.1 \mathrm{ng} / \mathrm{mL}$ ). Antiplasmodial activity shown by trioxacarcin $\mathrm{B}\left(\mathrm{IC}_{50}\right.$ value is $102 \pm 4.9 \mathrm{ng} / \mathrm{mL}$ ) was about 100 times less than trioxacarcins $\mathrm{A}$ and $\mathrm{D}$, while trioxacarcin $\mathrm{C}$ was nearly inactive $\left(\mathrm{IC}_{50}\right.$ value is $\left.>5000 \mathrm{ng} / \mathrm{mL}\right)$ [20].

Coronamycin is a complex of novel peptide antibiotics isolated by Strobel et al. in 2004 [30]. This compound is isolated from endophytic Streptomyces sp. from an epiphytic vine, Monstera sp., which can be found growing in the upper Amazon region of Peru [21]. Coronamycin demonstrated antiplasmodial activity against $P$. falciparum, with an $\mathrm{IC}_{50}$ of $9.0 \mathrm{ng} / \mathrm{mL}$. While coronamycin does not exhibit anticancer activity against breast cancer cell line (BT20), its cytotoxicity to primary human mammary epithelial cell line (HMEC) is comparable to taxol, an anticancer chemotherapy drug [21].

In 2002, Strobel and coworkers discovered a series of unique wide-spectrum antibiotics called munumbicins (A, B, $\mathrm{C}$, and $\mathrm{D}$ ). Munumbicin D caught the most attention as it shows an activity against the malarial parasite $P$. falciparum, with an $\mathrm{IC}_{50}$ of $4.5 \pm 0.07 \mathrm{ng} / \mathrm{mL}$ [23]. Another bioactive compound which has demonstrated antimalarial activity against P. falciparum was discovered in 2003 and has been identified as kakadumycin A. Kakadumycin A isolated from Streptomyces sp. NRRL 30566 yielded an $\mathrm{IC}_{50}$ of $7.04 \pm 0.12 \mathrm{ng} / \mathrm{mL}$ when testing against malarial parasite P. falciparum [25]. Strobel and coworkers continue to make a discovery and isolated two novel peptides, munumbicins E-4 and E-5, from an endophytic Streptomyces NRRL 30562, isolated from Kennedia nigricans, snake vine, in the Northern Territory of Australia. These compounds showed an antimalarial activity against $P$. falciparum with $\mathrm{IC}_{50}$ values of $0.50 \pm 0.08$ and $0.87 \pm 0.0 .26 \mathrm{mg} / \mathrm{mL}$ for E-4 and E-5, respectively [22]

Another bioactive compound that has shown an antimalarial activity is Gancidin-W, which has been isolated from Streptomyces sp. SUK 10. In vivo testing of GancidinW on Plasmodium berghei NK 65-infected mice showed an inhibition of $80 \%$ of the parasite at the concentration of 6.25 and $3.125 \mu \mathrm{g} / \mathrm{kg}$ body weight on final day of the test. In addition, $50 \%(n-3)$ of mice treated with Gancidin-W at concentration of $3.125 \mu \mathrm{g} / \mathrm{kg}$ body weight survived until 11 months after inoculation of infection [26].

Bioassay-guided fractionation of the extract from the fermentation broth of Streptomyces spectabilis BCC 4785 led to the isolation of metacycloprodigiosin. This compound showed potent in vitro activity against $P$. falciparum $\mathrm{K} 1$, with $\mathrm{IC}_{50}$ of $0.0050 \pm 0.0010 \mu \mathrm{g} / \mathrm{ml}$, while bafilomycin $\mathrm{A}_{1}$ isolated from Streptomyces sp. CS showed antimalarial activity against P. falciparum $\mathrm{K}_{1}$ with $\mathrm{IC}_{50}$ value of $0.041 \pm 0.010 \mu \mathrm{g} / \mathrm{mL}$ [24].

However, metabolomics approach has not been used or only partially used in all of the drug discovery works mentioned above. It could be because the scientist tends to search for activity of the particular compounds rather than thinking about the redundancy of the compounds. Along the process in bioassay-guided fractionation, the scientist could be missing some of the potentially active compounds due to inability to build in library at the prepurification stage. The use of metabolomics could help prioritize fractions for further purification which could save time and resources in isolating target compound [8].
4.1. Screening and Assessing for Antimalaria Activity of Natural Products. For the purpose of assessing antimalarial activity of the drugs, two methods have been developed: in vitro and in vivo methods. The details of each method are discussed below.

4.1.1. In Vitro Study. In vitro analysis is comprised of microscopy-based assay (also known as WHO microtest), tritium-labeled hypoxanthine assay (isotopic assays), fluorimetric assay (using DNA-specific dyes), cytometry-based assay, and enzyme-linked immunosorbent assay (ELISA) [31, 32]. Isotopic assay such as the tritium-labeled hypoxanthine assay allows rapid, sensitive, and accurate determination of parasite growth. This assay uses high degree of automatization and thus reduces variability that could be caused by human factors. Moreover, it also has been used for in vitro antimalarial drug sensitivity assay [31]. However, this assay has disadvantages, particularly due to the use of isotopic materials. The regulations on using and handling of radioactive compounds have become more restrictive since late 1970s due to the hazard that it may cause. Moreover, the technique is also considerably expensive with high cost of equipment such as scintillation counters and harvesting machine. Therefore, this isotopic assay has been replaced by more economical and safer alternative tests.

Fluorimetric assay with DNA-binding fluorescent dyes is a nonmorphological and nonradioactive assay [33]. This assay detects and measures the content of DNA of intact malaria-infected erythrocytes using specific fluorescent dyes that bind with the DNA [34]. This assay requires extra steps in its sample preparation to lyse the erythrocytes and to extract the DNA using chloroform in order to eliminate hemozoin that can cause quenching. This nonradioactive assay is simple, fast, and accurate with less expensive instrument use. However, the use of toxic dyes is a cause of concern. Ethidium bromide, for example, is a highly toxic and mutagenic compound that needs proper handling. Waste that contains this compound also requires specific and systematic disposal arrangement. Thus, this fluorometric assay should be revised and improvement needs to be made before this assay can be considered as an alternative standard method in this area of research.

An ELISA with monoclonal antibodies directed against either plasmodial lactate dehydrogenase $(\mathrm{pLDH})$ or histidine-rich protein II (HRP II) which were commonly used in drug discovery strategies because of either of the two is practical and less hazardous compared to others.

HRP II Testing. Histidine-rich protein II (PfHRP2) is natural $30 \mathrm{kDa}$ protein, part of cytoplasm of $P$. falciparum, heat stable which synthesized only by $P$. falciparum parasites [35]. This protein is very stable and had correlation between blood concentration of protein and parasite biomass [36]. According to [37] PfHRP2 was important factor in detoxification of heme. PfHRP2 was found in all strains of $P$. falciparum and in plasma and supernatant of culture as dissolved protein. PfHRP2 also was found on the surface of infected erythrocytes membrane. PfHRP2 contains 35\% histidine, $40 \%$ alanine, and $12 \%$ aspartate but the percentages of these amino acids vary depends on the isolate [38]. 
P. falciparum that penetrates human erythrocyte will grow and divide into new parasite within 48 hours. This parasite ingests up to $80 \%$ of the host hemoglobin through a protozoan, phagocytic organelle known as the cytosome [39]. The hemoglobin is then transported into an acidic vacuole by the cytosome. In this vacuole, hemoglobin is broken down by proteolytic enzyme into small peptides to serve as nutrients for the parasite [40]. The degraded hemoglobin would form free toxic product as free heme. Later the free heme detoxication is changed by polymerization of free heme into inert hemozoin [41]

Screening using $P$. falciparum maintained in vitro could be determined by using the PfHRP2 assay. Through this assay, PfHRP2 production could be used as an indicator for the growth of the parasite and the increasing of parasite in total [42]. The screening of PfHRP2 cannot be used for prediction of parasite response to treatment since the parasite antigen still presents persistence in blood circulation after parasite clearance [43]. However, this method has been successfully used in assessing the antimalaria activity of dihydroartemisinin, mefloquine, quinine, and chloroquine [44].

pLDH Assay. Plasmodium Lactate Dehydrogenase (pLDH) is an energy-producing enzyme and the final enzyme in parasite glycolytic pathway. It is soluble and is produced by sexual and asexual stages of all four human Plasmodium species [45]. This assay detects pLDH antigen, which is the specific marker for the presence of Plasmodium in sample. Based on this principle, this assay could detect malarial pLDH enzyme which utilized 3-acetylpyridine nicotinamide adenine dinucleotide (APAD) as NAD and nicotinamide adenine dinucleotide analogue, whereas erythrocyte $\mathrm{LDH}$ could not $[45,46]$. Pyruvate could be formed from Llactate as product in the presence of pLDH enzyme and APAD as coenzyme. This reaction produces a reduced form of APAD which in turn reduces nitro blue tetrazolium, a blue formazan product. This product could be detectable both visually and by spectrophotometer at $650 \mathrm{~nm} \mathrm{[34].} \mathrm{In}$ addition to enzymatic reaction described, two monoclonal antibodies specific for $P$. falciparum lactate dehydrogenase $(\mathrm{pLDH})$ were used to develop a double-site enzyme-linked LDH immunodetection assay (DELI) or in vitro assay. As a result, the DELI was a useful and practical method to determine the differential parasite growth in the presence of increasing drug concentrations, for example, to develop a simple colorimetric drug sensitivity assay [47], whereas munumbicin D [23] and kakadumycin A [25] are the example of antimalarial compounds that have been successfully tested using this method. This assay is useful for monitoring antimalarial therapy as well as to differentiate $P$. falciparum and other Plasmodium spp. [46].

\subsubsection{In Vivo Study}

Peter's Test. Four-day suppressive test which is also known as Peter's test is testing the efficacy of four daily doses of compounds. The testing is measured by comparing of blood parasitemia (on day four after infection) and mice survival time in treated and untreated mice [48]. The most widely used parasite is Plasmodium berghei [5]. This test is used to determine the antimalarial activity of candidates on early infections [49].

The infection of rodent could be initiated through needle passage from infected mice to naïve mice via intraperitoneal route using a small inoculum in range between $10^{6}$ and $10^{7}$ infected erythrocytes. Then, compound under study was administered through several routes such as intraperitoneal, intravenous, subcutaneous, or oral route. Recently, Gancidin$\mathrm{W}$, an antimalarial compound was successively tested using this methods [26].

Rane's Test. The purpose of this test is to evaluate the curative capability of candidate drug on established infections [49]. This test measures the ability of a standard inoculum of $P$. berghei to kill the recipient mice within 6 days of inoculation. Extension of survival beyond 12 days is determined to have a positive activity [50].

Each of the mice received a standard inoculum intravenously and treatment was withheld for $72 \mathrm{~h}$ to allow parasitaemia to establish. Blood smears were made from the tail blood of each mouse on five consecutive days, starting from the day of treatment. Average percentage parasitaemia was assessed. The number of deaths was also recorded for 28 days and the mean survival time is obtained afterward. Previous study has successfully been conducted by using this method in testing the antimalarial activity by combining two compounds, which were cryptolepine and artemisinins [51].

\section{Metabolomics Platform}

Metabolomics approach is critically dependent on technologies to identify and characterize chemical entities [52]. Three methods can be utilized for metabolomics platform which are Liquid Chromatography-Mass Spectrophotometry (LCMS), Gas Chromatography-Mass Spectrophotometry (GCMS), and Nuclear Magnetic Resonance (NMR) spectroscopy.

LC-MS platform is a very useful tool in analysing a wide range of semipolar compounds including many secondary metabolites of interest [53]. The coupling of liquid chromatography to mass spectrometers with high mass resolution (typically > 5,000 full width at half maximum (FWHM)) and high mass accuracy (typically $<5 \mathrm{ppm}$ ) provides high chromatographic resolution with high mass accuracy for detection of putative metabolite identification. Furthermore, LC-MS provides detection of higher-molecular-weight compounds of medium-to-high lipophilicity, including many classes of lipids (glycerolipids, phospholipids, fatty acids, bile acids, and sterols). Besides, sample preparation for LC-MS analysis only involved deproteinization, lyophilization, and reconstitution in a suitable aqueous/organic solvent mixture [54]. LC-MS provides a versatile tool to undergo the majority of analytical tasks in metabolite profiling studies.

Otherwise, GC-MS is used to analyse the volatile organic compounds (VOCs) [53]. GC-MS methods provide the detection of low-molecular-weight metabolites with a boiling point (either before or after chemical derivatisation) low enough to allow elution through a GC column. The boiling points of these metabolites are typically below $300^{\circ} \mathrm{C}$. 
Metabolites detectable using this method include amino and organic acids, fatty acids, carbohydrates, phosphorylated metabolites (such as glucose-6-phosphate), and cholesterol [54]. GC-MS is easy to operate and is a low cost instrument. However, the sample preparation is tedious, time-consuming, and prone to many errors. Nonvolatile metabolites may be converted into different forms of derivatives during the derivatisation reaction, thus producing a specimen where different forms of the same parent metabolite exist together. In addition, there is an issue of by-product formation and degradation. Depending on the conditions, metabolites are derivatised with different conversion rates [55]. Moreover, inaccurate quantification also might occur due to incomplete derivatisation. However, there are some strategies which can be applied to tackle this such as by using both derivatised standard compounds and by applying data correction strategies to normalize the bias. GC-MS by its nature is limited to the analysis of small volatile molecules and molecules that can be made volatile [56].

Proton nuclear magnetic resonance $\left({ }^{1} \mathrm{H}-\mathrm{NMR}\right)$ spectroscopy is one of the most popular methods in metabolomics approach. This technique is useful for the analysis of bulk metabolites [53]. It requires simple and nontedious sample preparation steps and produces reproducible result. This method has low sensitivity compared to other methods and only allows for the detection of the most abundant metabolites. Besides that, the cost to run the sample by NMR instrument is also relatively high. As a result availability of NMR spectroscopy and time available for this instrument for this type of work are both limited [56].

\section{Conclusion and Future Perspectives}

The metabolomics is a great opportunity, as this technique provides extra knowledge and information for the analysis of natural products and it provides dereplication of drugs redundancy to shorten the long process in drug discovery. In addition, this technology helps to identify and to optimize the production of secondary metabolites. The coupling with the other "omics" can be made with the help of chemometrics or bioinformatics. In general, metabolomics approach in malaria drug discovery especially in Malaysia is still new and needs to be initiated. As this technique offers a new dimension of research, it could maximise the potential of discovering novel therapeutic antimalaria compounds from the natural product especially in drug research in Malaysia.

\section{Conflicts of Interest}

The authors declare that there are no conflicts of interest regarding the publication of this paper.

\section{Acknowledgments}

The authors greatly acknowledge the Ministry of Higher Education (Grant no. FRGS/1/2016/STG05/UKM/02/5) for financial support.

\section{References}

[1] M. Lahlou, "Screening of natural products for drug discovery," Expert Opinion on Drug Discovery, vol. 2, no. 5, pp. 697-705, 2007.

[2] D. J. Newman, G. M. Cragg, and K. M. Snader, "The influence of natural products upon drug discovery," Natural Product Reports, vol. 17, no. 3, pp. 215-234, 2000.

[3] S. Smaoui, F. Mathieu, L. Elleuch et al., "Taxonomy, purification and chemical characterization of four bioactive compounds from new Streptomyces sp. TN256 strain," World Journal of Microbiology and Biotechnology, vol. 28, no. 3, pp. 793-804, 2012.

[4] F. Van Middlesworth and R. J. Cannell, "Dereplication and partial identification of natural products," in Natural Products Isolation, R. J. P. Cannell, Ed., vol. 4 of Methods in Biotechnology, pp. 279-327, Humana Press, Totowa, NJ, USA, 1998.

[5] T. Ito and M. Masubuchi, "Dereplication of microbial extracts and related analytical technologies," Journal of Antibiotics, vol. 67, no. 5, pp. 353-360, 2014.

[6] F. Carnevale Neto, A. C. Pilon, D. M. Selegato et al., "Dereplication of natural products using GC-TOF mass spectrometry: improved metabolite identification by spectral deconvolution ratio analysis," Frontiers in Molecular Biosciences, vol. 3, no. 2, 2016.

[7] L. Dinan, "Dereplication and partial identification of compounds," in Natural Products Isolation, S. D. Sarker, Z. Latif, and A. I. Gray, Eds., pp. 297-321, Humana Press, Totowa, NJ, USA, 2005.

[8] A. L. Harvey, R. Edrada-Ebel, and R. J. Quinn, "The reemergence of natural products for drug discovery in the genomics era," Nature Reviews Drug Discovery, vol. 14, no. 2, pp. 111-129, 2015.

[9] A. F. Tawfike, C. Viegelmann, and R. Edrada-Ebel, "Metabolomics and dereplication strategies in natural products," Methods in Molecular Biology, vol. 1055, pp. 227-244, 2013.

[10] S. Rochfort, "Metabolomics reviewed: A new "omics” platform technology for systems biology and implications for natural products research," Journal of Natural Products, vol. 68, no. 12, pp. 1813-1820, 2005.

[11] D. S. Wishart, "Applications of metabolomics in drug discovery and development," Drugs in R and D, vol. 9, no. 5, pp. 307-322, 2008.

[12] A. L. Demain, "Microbial production of primary metabolites," Naturwissenschaften, vol. 67, no. 12, pp. 582-587, 1980.

[13] J. Bérdy, "Bioactive microbial metabolites," The Journal of Antibiotics, vol. 58, no. 1, pp. 1-26, 2005.

[14] F. Bourgaud, A. Gravot, S. Milesi, and E. Gontier, "Production of plant secondary metabolites: a historical perspective," Plant Science, vol. 161, no. 5, pp. 839-851, 2001.

[15] Q.-T. Nguyen, M. E. Merlo, M. H. Medema, A. Jankevics, R. Breitling, and E. Takano, "Metabolomics methods for the synthetic biology of secondary metabolism," FEBS Letters, vol. 586, no. 15, pp. 2177-2183, 2012.

[16] N. I. M. Sarmin, G. Y. A. Tan, C. M. M. Franco, R. Edrada-Ebel, J. Latip, and N. M. Zin, "Streptomyces kebangsaanensis sp. nov., an endophytic actinomycete isolated from an ethnomedicinal plant, which produces phenazine-1-carboxylic acid," International Journal of Systematic and Evolutionary Microbiology, vol. 63, no. 10, pp. 3733-3738, 2013.

[17] S. T. Williams, M. Goodfellow, G. Alderson, E. M. Wellington, P. H. Sneath, and M. J. Sackin, "Numerical Classification of 
Streptomyces and Related Genera," Microbiology, vol. 129, no. 6, pp. 1743-1813, 1983.

[18] D. J. Newman and G. M. Cragg, "Natural products as sources of new drugs over the last 25 years," Journal of Natural Products, vol. 70, no. 3, pp. 461-477, 2007.

[19] M. Nett, H. Ikeda, and B. S. Moore, "Genomic basis for natural product biosynthetic diversity in the actinomycetes," Natural Product Reports, vol. 26, no. 11, pp. 1362-1384, 2009.

[20] R. P. Maskey, E. Helmke, O. Kayser et al., "Anti-cancer and antibacterial trioxacarcins with high anti-malaria activity from a marine streptomycete and their absolute stereochemistry," Journal of Antibiotics, vol. 57, no. 12, pp. 771-779, 2004.

[21] D. Ezra, U. F. Castillo, G. A. Strobel et al., "Coronamycins, peptide antibiotics produced by a verticillate Streptomyces sp. (MSU-2110) endophytic on Monstera sp," Microbiology, vol. 150, no. 4, pp. 785-793, 2004.

[22] U. F. Castillo, G. A. Strobel, K. Mullenberg et al., "Munumbicins E-4 and E-5: Novel broad-spectrum antibiotics from Streptomyces NRRL 3052," FEMS Microbiology Letters, vol. 255, no. 2, pp. 296-300, 2006.

[23] U. F. Castillo, G. A. Strobel, E. J. Ford et al., "Munumbicins, wide-spectrum antibiotics produced by Streptomyces NRRL 30562, endophytic on Kennedia nigriscans," Microbiology, vol. 148, no. 9, pp. 2675-2685, 2002.

[24] M. Isaka, A. Jaturapat, J. Kramyu, M. Tanticharoen, and Y. Thebtaranonth, "Potent in vitro antimalarial activity of metacycloprodigiosin isolated from Streptomyces spectabilis BCC 4785," Antimicrobial Agents and Chemotherapy, vol. 46, no. 4, pp. 1112-1113, 2002.

[25] U. Castillo, J. K. Harper, G. A. Strobel et al., "Kakadumycins, novel antibiotics from Streptomyces sp. NRRL 30566, an endophyte of Grevillea pteridifolia," FEMS Microbiology Letters, vol. 224, no. 2, pp. 183-190, 2003.

[26] N. M. Zin, M. S. Baba, A. H. Zainal-Abidin, J. Latip, N. W. Mazlan, and R. Edrada-Ebel, "Gancidin W, a potential low-toxicity antimalarial agent isolated from an endophytic Streptomyces SUK10," Drug Design, Development and Therapy, vol. 11, pp. 351-363, 2017.

[27] L.-L. Yan, N.-N. Han, Y.-Q. Zhang et al., "Antimycin $A_{18}$ produced by an endophytic Streptomyces albidoflavus isolated from a mangrove plant," The Journal of Antibiotics, vol. 63, no. 5, pp. 259-261, 2010.

[28] J. Li, C. Lu, and Y. Shen, "Macrolides of the bafilomycin family produced by Streptomyces sp. CS," Journal of Antibiotics, vol. 63, no. 10, pp. 595-599, 2010.

[29] F. Tomita, T. Tamaoki, M. Morimoto, and K. Fujimoto, "Trioxacarcins, novel antitumor antibiotics. I. Producing organism, fermentation and biological activities," Journal of Antibiotics, vol. 34, no. 12, pp. 1519-1524, 1981.

[30] G. Strobel, B. Daisy, U. Castillo, and J. Harper, "Natural products from endophytic microorganisms," Journal of Natural Products, vol. 67, no. 2, pp. 257-268, 2004.

[31] L. K. Basco, E. Heseltine, and W. H. Organization, Field application of in vitro assays for the sensitivity of human malaria parasites to antimalarial drugs, 2007.

[32] H. Noedl, C. Wongsrichanalai, and W. H. Wernsdorfer, "Malaria drug-sensitivity testing: New assays, new perspectives," Trends in Parasitology, vol. 19, no. 4, pp. 175-181, 2003.

[33] W. Trager and J. B. Jensen, "Human malaria parasites in continuous culture," Science, vol. 193, no. 4254, pp. 673-675, 1976.
[34] L. K. Basco, F. Marquet, M. M. Makler, and J. Lebras, "Plasmodium falciparum and Plasmodium vivax: LactateDehydrogenase Activity and Its Application for in Vitro Drug Susceptibility Assay," Experimental Parasitology, vol. 80, no. 2, pp. 260-271, 1995.

[35] R. J. Howard, S. Uni, M. Aikawa et al., "Secretion of a malarial histidine-rich protein (Pf HRP II) from Plasmodium falciparum-infected erythrocytes," Journal of Cell Biology, vol. 103, no. 4, pp. 1269-1277, 1986.

[36] V. Desakorn, K. Silamut, B. Angus et al., "Semi-quantitative measurement of Plasmodium falciparum antigen PfHRP2 in blood and plasma," Transactions of the Royal Society of Tropical Medicine and Hygiene, vol. 91, no. 4, pp. 479-483, 1997.

[37] A. V. Pandey, H. Bisht, V. K. Babbarwal, J. Srivastava, K. C. Pandey, and V. S. Chauhan, "Mechanism of malarial haem detoxification inhibition by chloroquine," Biochemical Journal, vol. 355, no. 2, pp. 333-338, 2001.

[38] T. E. Wellems and R. J. Howard, "Homologous genes encode two distinct histidine-rich proteins in a cloned isolate of Plasmodium falciparum.," Proceedings of the National Academy of Sciences, vol. 83, no. 16, pp. 6065-6069, 1986.

[39] D. E. Goldberg, A. F. Slater, A. Cerami, and G. B. Henderson, "Hemoglobin degradation in the malaria parasite Plasmodium falciparum: an ordered process in a unique organelle.," Proceedings of the National Academy of Sciences, vol. 87, no. 8, pp. 29312935, 1990.

[40] S. R. Meshnick, "Is haemozoin a target for antimalarial drugs?" Annals of Tropical Medicine \& Parasitology, vol. 90, no. 4, pp. 367-372, 2016.

[41] A. F. G. Slater and A. Cerami, "Inhibition by chloroquine of a novel haem polymerase enzyme activity in malaria trophozoites," Nature, vol. 355, no. 6356, pp. 167-169, 1992.

[42] V. Desakorn, A. M. Dondorp, K. Silamut et al., "Stagedependent production and release of histidine-rich protein 2 by Plasmodium falciparum," Transactions of the Royal Society of Tropical Medicine and Hygiene, vol. 99, no. 7, pp. 517-524, 2005.

[43] S. Houzé, M. D. Boly, J. Le Bras, P. Deloron, and J.-F. Faucher, "PfHRP2 and PfLDH antigen detection for monitoring the efficacy of artemisinin-based combination therapy (ACT) in the treatment of uncomplicated falciparum malaria," Malaria Journal, vol. 8, no. 1, article no. 211, 2009.

[44] H. Noedl, B. Attlmayr, W. H. Wernsdorfer, H. Kollaritsch, and R. S. Miller, "A histidine-rich protein 2-based malaria drug sensitivity assay for field use," American Journal of Tropical Medicine and Hygiene, vol. 71, no. 6, pp. 711-714, 2004.

[45] D. J. Hinrichs and M. T. Makler, "Measurement of the lactate dehydrogenase activity of plasmodium falciparum as an assessment of parasitemia," The American Journal of Tropical Medicine and Hygiene, vol. 48, no. 2, pp. 205-210, 1993.

[46] M. T. Makler, C. J. Palmer, and A. L. Ager, "A review of practical techniques for the diagnosis of malaria," Annals of Tropical Medicine and Parasitology, vol. 92, no. 4, pp. 419-433, 1998.

[47] P. Druilhe, A. Moreno, C. Blanc, P. H. Brasseur, and P. Jacquier, "A colorimetric in vitro drug sensitivity assay for Plasmodium falciparum based on a highly sensitive double-site lactate dehydrogenase antigen-capture enzyme-linked immunosorbent assay," American Journal of Tropical Medicine and Hygiene, vol. 64, no. 5, pp. 233-241, 2001.

[48] W. Peters, "The value of drug-resistant strains of Plasmodium berghei in screening for blood schizontocidal activity," Annals of Tropical Medicine and Parasitology, vol. 69, no. 2, pp. 155-171, 1975. 
[49] L. Bantie, S. Assefa, T. Teklehaimanot, and E. Engidawork, "In vivo antimalarial activity of the crude leaf extract and solvent fractions of Croton macrostachyus Hocsht. (Euphorbiaceae) against Plasmodium berghei in mice," BMC Complementary and Alternative Medicine, vol. 14, article 79, 2014.

[50] A. O. Abosi and B. H. Raseroka, "In vivo antimalarial activity of Vernonia amygdalina," British Journal of Biomedical Science, vol. 60, no. 2, pp. 89-91, 2003.

[51] A. D. Forkuo, C. Ansah, K. M. Boadu et al., "Synergistic anti-malarial action of cryptolepine and artemisinins," Malaria Journal, vol. 15, no. 1, article no. 89, 2016.

[52] W. B. Dunn, N. J. C. Bailey, and H. E. Johnson, "Measuring the metabolome: current analytical technologies," Analyst, vol. 130, no. 5, pp. 606-625, 2005.

[53] J. W. Allwood and R. Goodacre, "An introduction to liquid chromatography-mass spectrometry instrumentation applied in plant metabolomic analyses," Phytochemical Analysis, vol. 21, no. 1, pp. 33-47, 2010.

[54] W. B. Dunn, D. Broadhurst, P. Begley et al., "Procedures for large-scale metabolic profiling of serum and plasma using gas chromatography and liquid chromatography coupled to mass spectrometry," Nature Protocols, vol. 6, no. 7, pp. 1060-1083, 2011.

[55] H. Kanani, P. K. Chrysanthopoulos, and M. I. Klapa, "Standardizing GC-MS metabolomics," Journal of Chromatography B: Analytical Technologies in the Biomedical and Life Sciences, vol. 871, no. 2, pp. 191-201, 2008.

[56] G. A. Theodoridis, H. G. Gika, E. J. Want, and I. D. Wilson, "Liquid chromatography-mass spectrometry based global metabolite profiling: A review," Analytica Chimica Acta, vol. 711, pp. 7-16, 2012. 


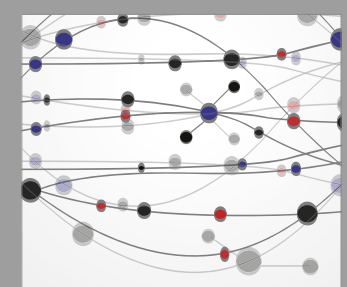

The Scientific World Journal
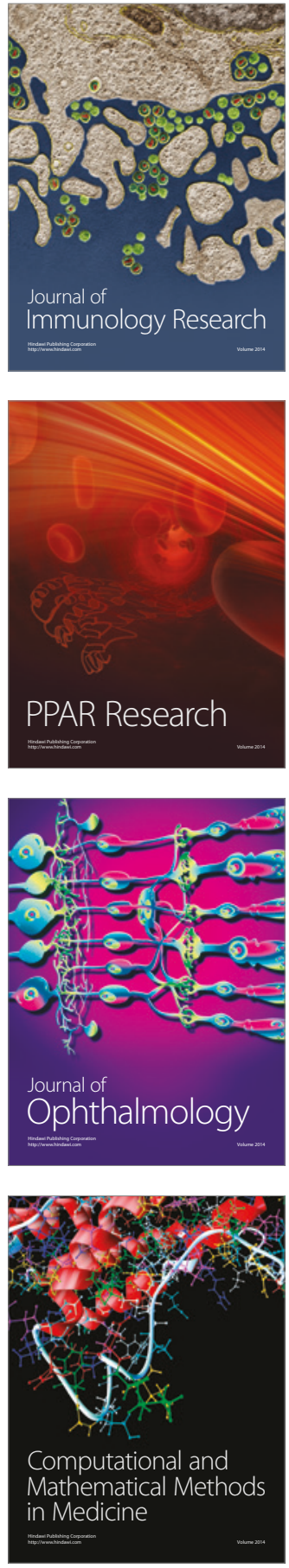

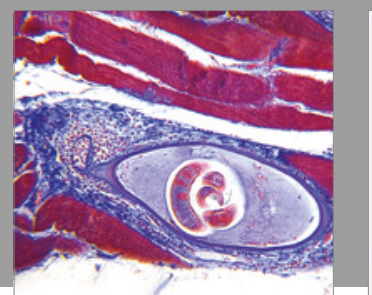

Gastroenterology Research and Practice
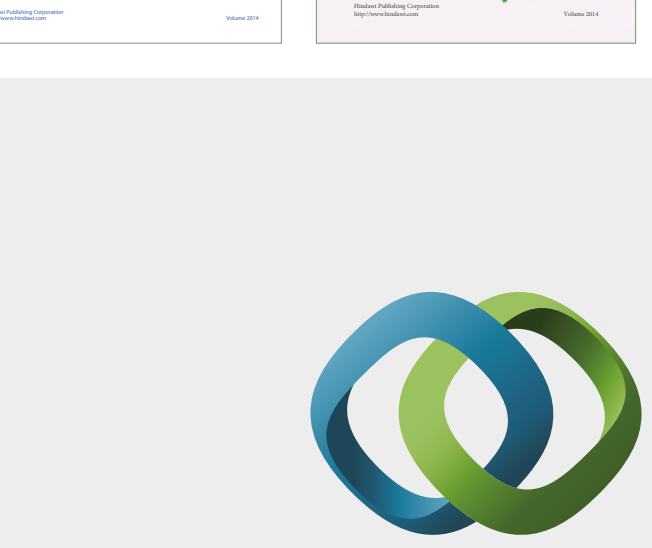

\section{Hindawi}

Submit your manuscripts at

https://www.hindawi.com
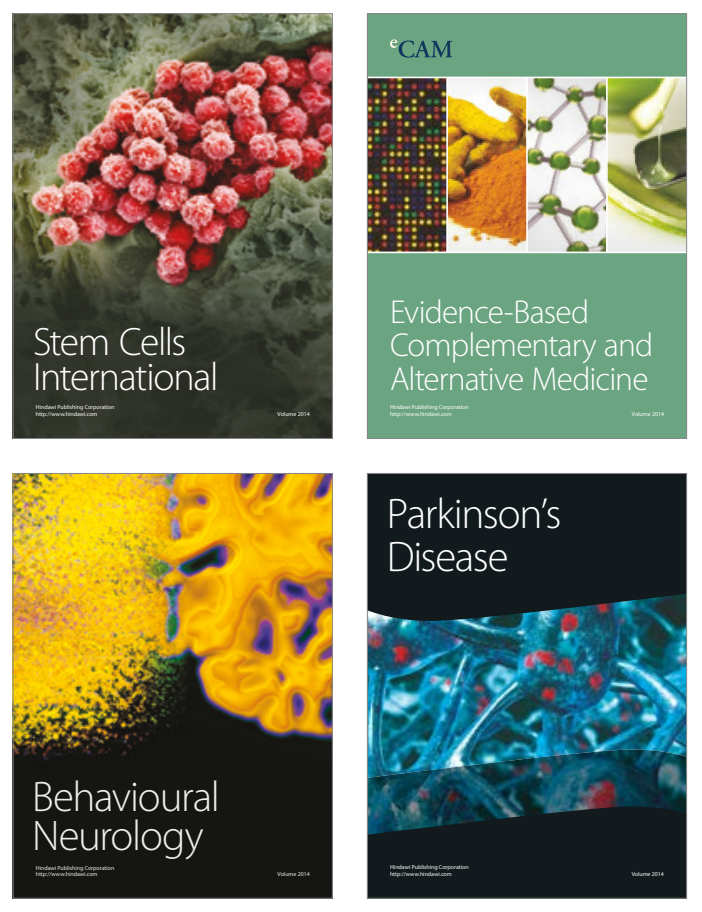
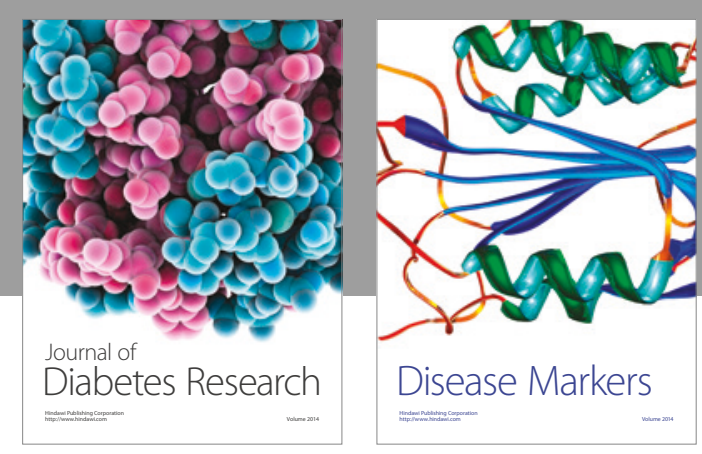

Disease Markers
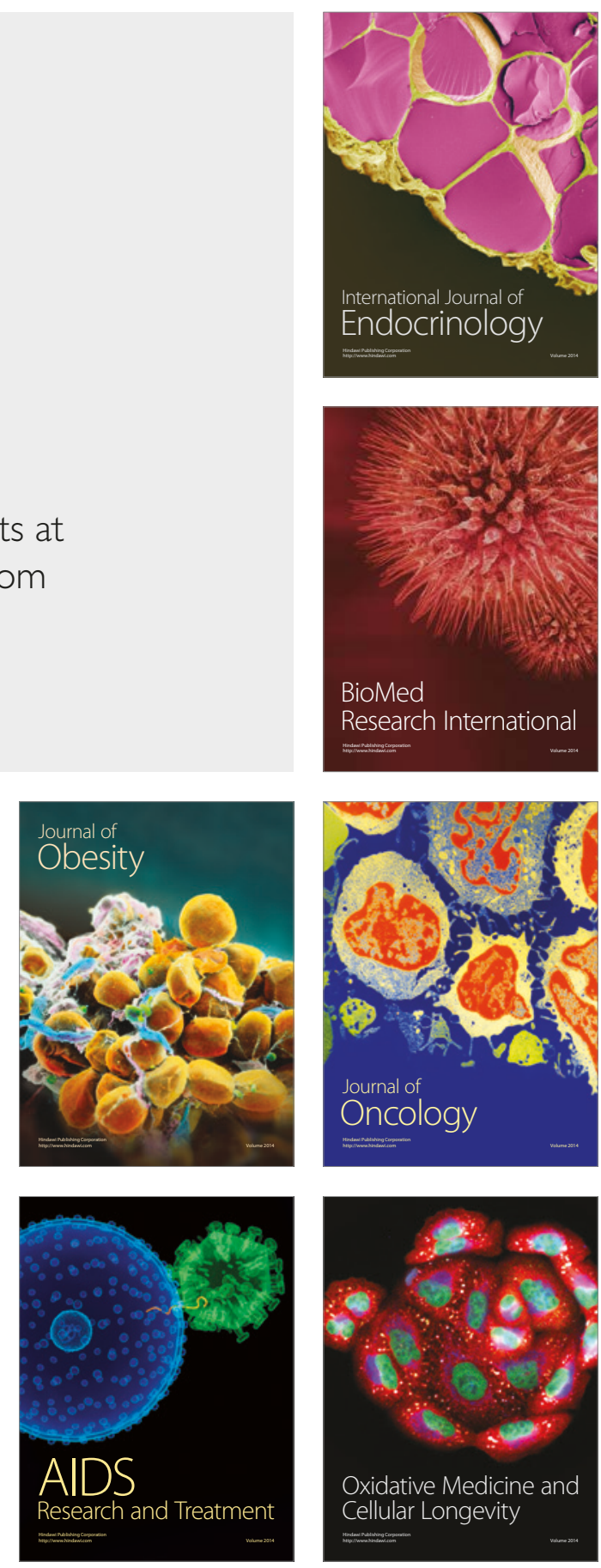